\title{
Modelling hydrological change due to wildfires
}

\author{
$\underline{\text { D. Partington }}^{\text {a }}$, M. Thyer $^{\text {b }}$, M. Shanafield ${ }^{\text {a }}$, D. McInerney ${ }^{\text {b }}$, S. Westra ${ }^{\text {b }}$, H.R. Maier ${ }^{\text {b }}$, \\ C.T. Simmons ${ }^{\text {a }}$, B.F.W. Croke ${ }^{\text {c }}$, A.J. Jakeman ${ }^{\text {c }}$, H.V. Gupta ${ }^{\text {d }}$ and D. Kavetski ${ }^{b}$ \\ ${ }^{a}$ College of Science and Engineering, Flinders University, South Australia, ${ }^{b}$ School of Civil, Environmental \\ and Mining Engineering, University of Adelaide, South Australia, ${ }^{c}$ Fenner School of Environment and \\ Society, The Australian National University, Australian Capital Territory, ${ }^{d}$ Hydrology and Atmospheric \\ Sciences, University of Arizona, Arizona \\ Email:daniel.partington@flinders.edu.au
}

\begin{abstract}
Wildfires are an important hydrological disturbance altering runoff by the fire induced changes (from heat and smoke) to vegetation and soils. The damage to both vegetation and soils creates immediate local changes to water portioning and associated runoff which can accumulate to catchment scale changes. Such changes are dynamic depend on the subsequent recovery of soils and regrowth/recovery of vegetation. As the prevalence of wildfires increases due to a warming and drying climate, such disturbances are a necessary consideration in the management and associated modelling of water resources. The impact of wildfires on water resources decisions comes not only in the immediate aftermath of the fires, but throughout the recovery phase and over extended periods with multiple cycles of wildfire and growth. Associated with these three timescales are pertinent hydrological issues, i.e. flood risk, water quality, water allocations and planning of reservoir operations. Modelling the wildfire induced hydrological impacts at each of these timescales requires a focus on the dominant processes; hydroclimate/meteorological, vegetation, hydrological, fire spread and effects; the latter here is only of significance in consideration of future fires. Focusing on different levels of abstractions of the dominant processes has resulted in a diverse set of approaches across existing models. Here, we explore some of the existing models in the literature that have been applied in assessing wildfire induced changes to runoff. For the purposes of comparison we broadly categorise these models into one of three categories: data-driven, conceptual and physically-based (eco-)hydrological models. We consider their demonstrated applications (assessing changes to streamflow and baseflow, historical analysis of pre- and post-fire periods of streamflow, predicting long term changes to yield), process representations (implicit vs explicit, lumped vs distributed) and spatiotemporal scales (from plot scales over days to watersheds over decades). Based on these characteristics and considering the computational requirements, data type breadth needed and the ability to predict wildfire impacts on runoff for different fires in the future, we describe the key limitations of each model category. With the significant changes to hydrological functioning that are possible after wildfire, physically-based models that utilize physical and biological principals are likely to receive increased attention with their perceived ability to extrapolate outside of the historical record. However, the computational and data costs of physically-based models are limiting the ability to completely support water resources planning. We argue that overcoming such limitations, while leveraging strengths, is possible through adoption of a hybrid modelling approach which combines computationally efficient conceptual models with reduced-order models. Such a hybrid approach would enable the requisite simulations of wildfire-induced changes to runoff for critical water resources planning scenarios.
\end{abstract}

Keywords: Disturbance hydrology, wildfire, hydrological change, hydrological modelling 


\section{INTRODUCTION}

In the emerging field of disturbance hydrology, wildfire disturbances are an increasingly important area of research (Mirus et al., 2017). Modelling hydrological change arising from wildfires is becoming increasingly pertinent due to the risks to water supply from increases in severity and frequency of wildfire events (Robinne et al., 2021). Wildfires impact upon hydrological and ecological functioning primarily through modification of vegetation and soils. The changes caused to vegetation and soils result in significant impacts (at different times) such as flooding, reduced yield and water quality issues.

From a process point of view, understanding the role of wildfires in the context of predicting runoff requires consideration of hydroclimate/meteorological processes, vegetation processes, water partitioning/hydrological processes, and fire spread and effects. Moreover, the interactions of each of these processes can lead to both positive and negative feedbacks (Figure 1). At the scale of a catchment (and smaller), the dominant/strong interactions between these process groups allow for simplification of hydroclimate/meteorological processes as just external forcing on the vegetation, hydrological and fire processes in a catchment system. In a runoff modelling context, these processes do not necessarily need to be explicitly nor implicitly considered if a strong record of previous fire events is present in a catchment.

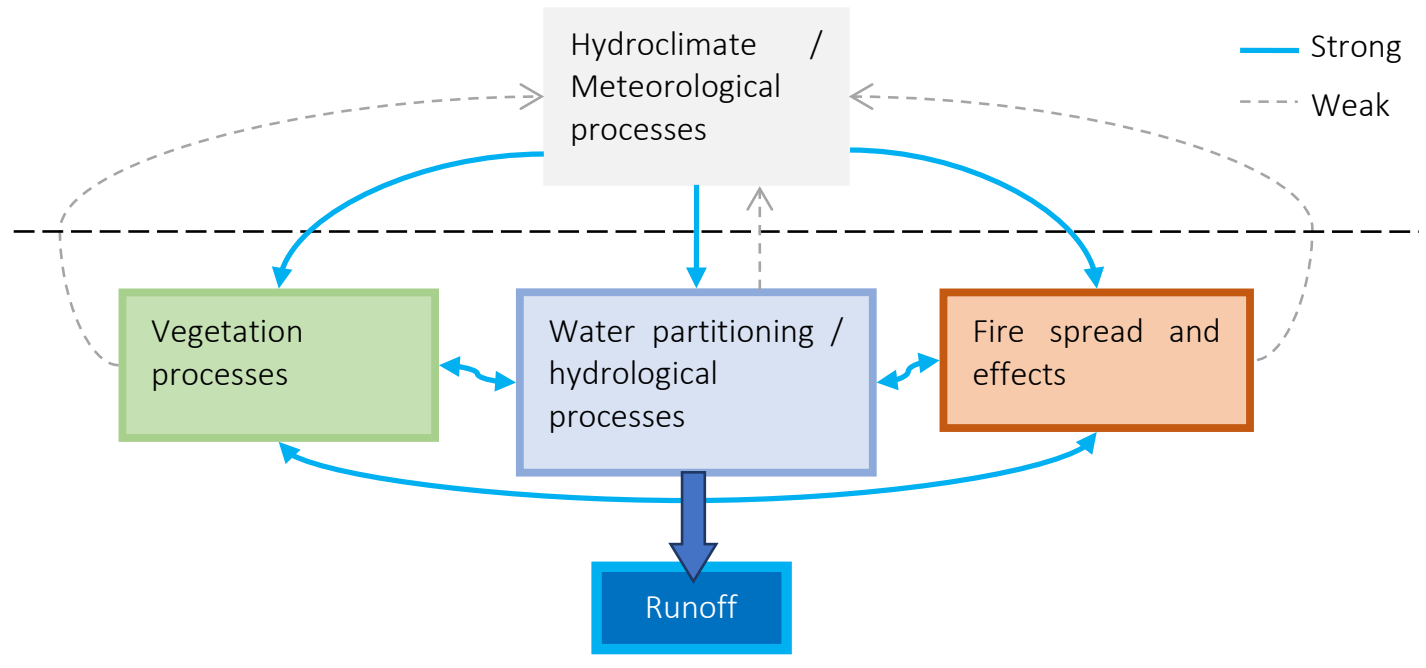

Figure 1. Key process categories and feedbacks relating to wildfires impact on hydrological response.

Where there is no historical record of fire or where the severity of fires has not been significant, it is hard to quantitatively predict the changes to runoff that might occur without full consideration of the processes in Figure 1. While wildfire is not the only disturbance that creates conditions outside of the historical record, it does act to reduce the predictive ability of hydrological models unable to explicitly account for wildfire induced modifications to hydrological functioning. Where wildfires are a threat, it thus contributes to land and water management considerations under future change. Despite this, there is still a lack of modelling applications accounting for wildfire impacts in support of water resources problems, likely attributable to insufficient data and a focus on small spatial scales.

In this paper, we look at the key processes driving wildfire induced hydrological change, how models are currently being used to help understand this, and the challenges and opportunities in modelling runoff following wildfire with data-driven, conceptual, and physically-based models. Through the lens of pertinent water resources problems, we consider whether available models are suitable to assist in addressing such problems. For each of these model classes, we consider a range of pertinent time-scales for runoff predictions. The three time-scales considered are short- (flood risk, water quality), medium- (water allocations), and long-term (planning of dams/desalination plants). This leads to an analysis of the advantages and limitations of each model type for adequately capturing relevant processes.

For different model types (data-based/conceptual/physically-based) their past use in wildfire related studies was identified and their ability to capture the key processes for the different scenarios was evaluated. For data-based models, the key strengths were the high computation speed, low data requirements and high ability (and past use) to predict wildfire impacts in catchments where there was a fire-affected record. There weakness is their limited capacity to predict wildfire impacts in catchments with no fire affected records. For physically-based models, the key strength was the ability to incorporate wildfire inducted process changes in 
soil and vegetation properties, as demonstrated by their past-use in such studies. However, there key weakness, was their low computational speed and high data requirements. Conceptual models have similar strengths to data-based models, but with limited ability (and past-use) to predict wildfire impacts, as they are missing explicit representation of key soil/vegetation processes.

In order to overcome the deficiencies and also exploit the strengths of different model types, a hybrid approach was identified as a viable option. Such a hybrid approach would seek to identify new conceptual/reduced-order models that are capable of capturing key wildfire induced process changes, informed by the physically-based models. Predicting runoff in a catchment at risk of wildfire with a hybrid modelling approach afford the use of scenario modelling, which is a necessary approach to account for climate change uncertainty and also explore optimal land/water management practices.

\section{IMPACTS OF WILDFIRE ON RUNOFF}

Wildfire impacts hydrological functioning across catchments through changes to the amount of water that makes it to the surface and how that water is partitioned. The wildfire induced changes in local flow partitioning cascade to ultimately impact the total runoff in streams (Figure 2). This change to runoff arises through two main sources (Figure 2). We briefly describe these here although further details of the key processes can be found in Partington et al. (2021) and references therein.

Firstly, wildfire burns vegetation, which drastically changes the land cover in the immediate term. The loss of tree canopy, understorey, and litter drastically reduces interception. This means that more water reaches the ground surface; this reduction in interception is dependent on the severity of fire. The loss of leaf area coverage also leads to less transpiration. Regrowth of some tree and plants can transpire more water in the juvenile growth stages before maturity is reached. Secondly, wildfire impacts upon soils and their hydraulic properties by burning of the soil, killing organics and ash deposition, inhibiting infiltration through changes to soil hydraulic properties. The most notable effects reducing infiltration capacity are often resolved within 5 years from a wildfire event although full recovery can take 20 years (Ebel and Martin, 2017).

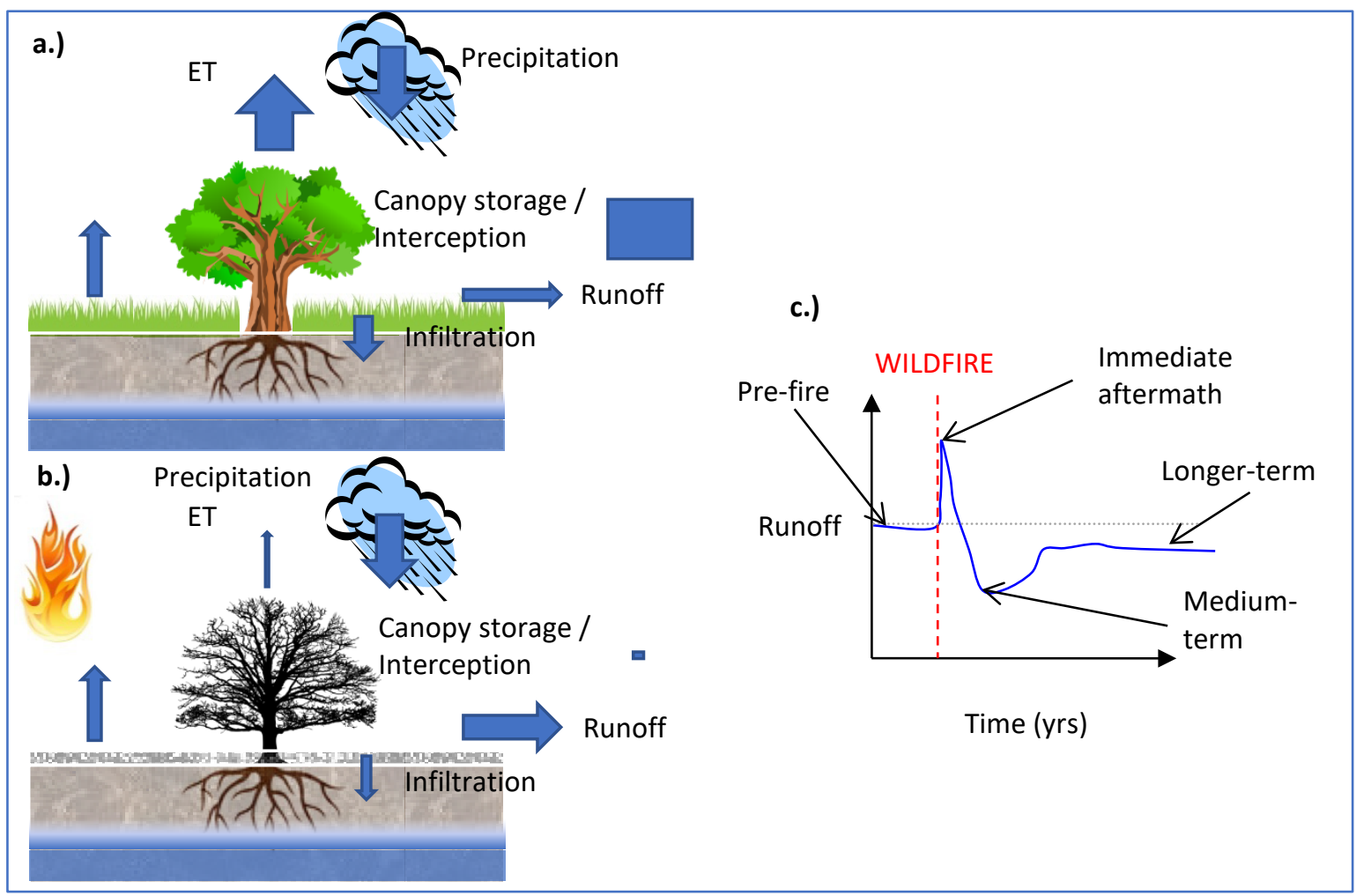

Figure 2. Soil and vegetation changes induced by wildfire (a. and b.) and the possible cumulative effects to runoff at different time-scales (c.).

The immediate local combined changes to burning of vegetation and soils lead to change in runoff generation as there is less interception and less infiltration capacity. However, the severity of the wildfire event as well as the pre-fire state of vegetation influences changes to soil hydraulic properties and level of vegetation destruction. Of particular importance are the spatial patterns of burnt areas and the proportion of catchment 
burnt, which influence whether burnt areas are connected to the stream, their size, and the extent of that connection. Burnt areas that are well connected to streams will allow local impacts of less interception and infiltration to be noticed in the stream but a buffer of vegetation between the burnt area and stream will strongly dampen local effects with respect to stream flow.

\section{WHAT DO MODELS NEED TO PREDICT WILDFIRE INDUCED CHANGES TO RUNOFF NEED?}

The differing temporal scales (and resolutions) and associated dynamics result in differences in the importance of various processes over time. For example, in modelling runoff in the immediate wildfire aftermath, it is important to account for the soil property changes. In the medium-term, where vegetation regrowth and recovery dominate, it is important to model ET processes more thoroughly. For longer-term simulations, it is important to incorporate wildfire cycles and the associated regrowth and recovery into the modelling (Table 1).

Table 1. Modelling timescales, associated process representation and relevant impacts for post- fire conditions (adapted from Partington et al. (2021)).

\begin{tabular}{|l|l|l|l|l|}
\hline $\begin{array}{l}\text { Timescale } \\
\text { [modelling } \\
\text { timestep] }\end{array}$ & Fire processes & $\begin{array}{l}\text { Vegetation } \\
\text { processes }\end{array}$ & Soil processes & $\begin{array}{l}\text { Potential } \\
\text { impacts to } \\
\text { runoff }\end{array}$ \\
\hline $\begin{array}{l}\text { Immediate } \\
\text { aftermath } \\
\text { [hourly/ daily] }\end{array}$ & $\begin{array}{l}\text { Single fire } \\
\text { spread/effects } \\
\text { (burn area and } \\
\text { severity) }\end{array}$ & $\begin{array}{l}\text { Unburnt } \\
\text { vegetation } \\
\text { cover }\end{array}$ & $\begin{array}{l}\text { Changes to } \\
\text { SHP (water } \\
\text { repellency, ash } \\
\text { deposition) }\end{array}$ & $\begin{array}{l}\text { Increased } \\
\text { peaks, shorter } \\
\text { duration of } \\
\text { flow }\end{array}$ \\
\hline $\begin{array}{l}\text { Recovery phase } \\
\text { [daily/ monthly] }\end{array}$ & $\begin{array}{l}\text { Single fire spread } \\
\text { /effects (burn area } \\
\text { and severity) }\end{array}$ & $\begin{array}{l}\text { Mortality / } \\
\text { regrowth }\end{array}$ & Recovery & $\begin{array}{l}\text { Decreased } \\
\text { runoff }\end{array}$ \\
\hline $\begin{array}{l}\text { Extended periods } \\
\text { with multiple } \\
\text { cycles of wildfire } \\
\text { and regrowth }\end{array}$ & $\begin{array}{l}\text { Multiple fires } \\
\text { spread/effects } \\
\text { (burn areas and } \\
\text { severities) }\end{array}$ & $\begin{array}{l}\text { Mortality / } \\
\text { regrowth } \\
\text { maturation of } \\
\text { trees }\end{array}$ & $\begin{array}{l}\text { N/A (assumed } \\
\text { insignificant at } \\
\text { long-term } \\
\text { timescale) }\end{array}$ & $\begin{array}{l}\text { Long-term } \\
\text { yield changes }\end{array}$ \\
\hline
\end{tabular}

\section{EVALUATION OF MODELS USED FOR QUANTIFYING WILDFIRE IMPACTS ON RUNOFF}

In this section we briefly explore the different types of models and their demonstrated uses in modelling hydrological changes associated with wildfires. A more in-depth overview of the corresponding literature can be found in Partington et al. (2021). For this exploration, we broadly group models into one of three categories: data-driven, conceptual and physically-based. It is acknowledged that there is a particular nuance to such a broad grouping; however, it provides a useful separation of themes and applications for the differing models.

Data-driven models, also commonly known as 'empirical' or 'statistical' models, do not explicitly consider changes to both soil and vegetation and their spatial organization, nor are they intended to. Rather these models formulate empirical relationships between some quantity of interest (typically streamflow) and other selected covariates (e.g. rainfall, area burnt in wildfire). There are numerous examples of such models having been used to assess wildfire induced changes to annual streamflow and baseflow (e.g., Bart and Tague, 2017; Kuczera, 1987; Wine et al., 2018).

Conceptual models, as their name suggests, consist of conceptual components and are usually lumped at the catchment scale. There use in assessing wildfire impacts is limited to quantifying or detecting past change through historical analysis of pre-fire and post-fire periods (e.g., Seibert et al., 2010; Zhou et al., 2015). However, there is no clear strategy for modifying the parameters to account for the wildfire induced hydrological change. 
Physically-based models often attempt to represent environmental physics in as much detail as possible and are employed using a spatial discretization. This class of models often has a focus on either fully integrating a complex representation of surface and subsurface flow (solving a collection of partial differential equations) (e.g., Ebel et al., 2016; Maina and Siirila-Woodburn, 2020), or a focus on complex vegetation dynamics (with a large collection of interacting sub-models that simulate the water, energy, and carbon fluxes, nutrient cycling as well as vegetation growth) (e.g., Boisramé et al., 2019; Feikema et al., 2013).

A summary of the above different model types ability to be used for scenario-based decision making, their data requirements and ability to predict wildfire impacts is summarized below in Table 2 .

Table 2. Summary of data-driven, conceptual and physically-based models' strengths and weaknesses for capturing wildfire induced changes to runoff with consideration of different impact timescales (adapted from Partington et al. (2021)).

\begin{tabular}{|l|c|c|c|}
\hline & Data-Driven & Conceptual & Physically-Based \\
\hline $\begin{array}{l}\text { Suitability for scenario } \\
\text { based decision making } \\
\text { (computational speed) }\end{array}$ & High & High & Low \\
\hline $\begin{array}{l}\text { Data type breadth } \\
\text { requirement }\end{array}$ & Low & Low & High \\
\hline \multirow{2}{*}{$\begin{array}{l}\text { Ability to predict wildfire } \\
\text { impacts on runoff }\end{array}$} & $\begin{array}{c}\text { Medium } \\
\text { (with fire affected record) }\end{array}$ & $\begin{array}{c}\text { Low }{ }^{*} \\
\text { Short-term: No soil proc. } \\
\text { Med-term: No soil/veg proc. } \\
\text { (no fire affected record) }\end{array}$ & $\begin{array}{l}\text { Long-term: No veg. proc } \\
\text { (Short-term: ISSHM) }\end{array}$ \\
\cline { 2 - 4 } & (Medium- and Long-term: \\
FDEM)
\end{tabular}

* In theory conceptual models may exhibit analogous 'high' performance to data-driven models when calibrated to fire-affected records; however at the time of writing no studies were identified that used conceptual models in this manner.

Additionally, their usefulness in predicting runoff can be summarized as follows:

- Data-driven models are fast, have low data requirements, a high ability to predict with fire-affected record but suffer weakness when no fire-affected record exists for catchments.

- Conceptual models have similar characteristics to the data-driven models but limited ability to predict impacts as key soil/vegetation processes are missing.

Physically-based models demonstrate strength in their explicit incorporation of soil/vegetation processes but encumbered by computational speed and significant data requirements and the differing models preference to particular processes, i.e. no single model makes pragmatic simplifications of either soil or vegetation processes.

\section{A HYBRID APPROACH}

Based on the limitations and strengths of existing models, a hybrid approach is desirable to get the best attributes from the different model types. As predictions of runoff are the focus, the dynamics of soil and vegetation are best captured by the physically-based models, although they suffer from the bottleneck of computational speed. Overcoming such a bottleneck can be done by using such models to inform computationally efficient conceptual models. This would likely require adding some more flexibility to the conceptual models by allowing time varying parameters. More broadly, the more complex physically-based models could be sped up through model surrogacy or emulation. The challenge with such an approach is avoiding the limitations of high computational demand and parameter non-identifiability.

\section{CONCLUSIONS}

Wildfire induced hydrological disturbances are increasingly garnering attention, with intense and large-scale wildfires sweeping across much of Australia and the American West, as well as several areas that have not previously been at risk of burning. These disturbances require inclusion in decision-making for securing our 
water resources, which in turn will necessitate modelling for prediction. The hydrological changes that are from such disturbances are dynamic, leading to both increases and decreases in runoff as vegetation and soil characteristics recover/change. The drivers of such dynamics need incorporation in hydrological modelling efforts.

Based on our evaluation, we conclude that a hybrid approach is desirable that can function with no fireaffected record, and tractable computational requirements while incorporating necessary soil/vegetation processes for the appropriate decision specific time-scale. Such an approach would allow for development of new conceptual/reduced-order models derived from the more cumbersome physically-based models. While the hybrid approach argued for here to address hydrological change caused by wildfire impacts, such an approach is likely of use more broadly in dealing with hydrological change brought on by other hydrological disturbances and/or changes.

\section{ACKNOWLEDGMENTS}

This research was supported by the Australian Government through the Australian Research Council's Discovery Projects funding scheme (project DP190102138).

\section{REFERENCES}

Bart, R.R., Tague, C.L., 2017. The impact of wildfire on baseflow recession rates in California. Hydrological Processes 31(8) 1662-1673.

Boisramé, G.F.S., Thompson, S.E., Tague, C.L., Stephens, S.L., 2019. Restoring a Natural Fire Regime Alters the Water Balance of a Sierra Nevada Catchment. Water Resources Research 55(7) 5751-5769.

Ebel, B.A., Martin, D.A., 2017. Meta-analysis of field-saturated hydraulic conductivity recovery following wildland fire: Applications for hydrologic model parameterization and resilience assessment. Hydrological Processes 31(21) 3682-3696.

Ebel, B.A., Rengers, F.K., Tucker, G.E., 2016. Observed and simulated hydrologic response for a first-order catchment during extreme rainfall 3 years after wildfire disturbance. Water Resources Research 52(12) 9367-9389.

Feikema, P.M., Sherwin, C.B., Lane, P.N.J., 2013. Influence of climate, fire severity and forest mortality on predictions of long term streamflow: Potential effect of the 2009 wildfire on Melbourne's water supply catchments. Journal of Hydrology 488 1-16.

Kuczera, G., 1987. Prediction of water yield reductions following a bushfire in ash-mixed species eucalypt forest. Journal of Hydrology 94(3) 215-236.

Maina, F.Z., Siirila-Woodburn, E.R., 2020. Watersheds dynamics following wildfires: Nonlinear feedbacks and implications on hydrologic responses. Hydrological Processes 34(1) 33-50.

Mirus, B.B., Ebel, B.A., Mohr, C.H., Zegre, N., 2017. Disturbance Hydrology: Preparing for an Increasingly Disturbed Future. Water Resources Research 53(12) 10007-10016.

Partington, D., Thyer, M., Shanafield, M., McInerney, D., Westra, S., Maier, H.R., Simmons, C.T., Croke, B.F.W., Jakeman, A.J., Gupta, H., Kavetski, D., 2021. Predicting wildfire induced changes to runoff. Submitted to WIRES Water.

Robinne, F.-N., Hallema, D.W., Bladon, K.D., Flannigan, M.D., Boisramé, G., Bréthaut, C.M., Doerr, S.H., Di Baldassarre, G., Gallagher, L.A., Hohner, A.K., Khan, S.J., Kinoshita, A.M., Mordecai, R., Nunes, J.P., Nyman, P., Santín, C., Sheridan, G., Stoof, C.R., Thompson, M.P., Waddington, J.M., Wei, Y., 2021. Scientists' warning on extreme wildfire risks to water supply. Hydrological Processes 35(5) e14086.

Seibert, J., McDonnell, J.J., Woodsmith, R.D., 2010. Effects of wildfire on catchment runoff response: a modelling approach to detect changes in snow-dominated forested catchments. Hydrology Research 41(5) 378-390.

Wine, M.L., Cadol, D., Makhnin, O., 2018. In ecoregions across western USA streamflow increases during post-wildfire recovery. Environmental Research Letters 13(1) 014010.

Zhou, Y., Zhang, Y., Vaze, J., Lane, P., Xu, S., 2015. Impact of bushfire and climate variability on streamflow from forested catchments in southeast Australia. Hydrological Sciences Journal 60(7-8) $1340-1360$. 